\title{
Trading Kyoto
}

\author{
GLEN P. PETERS AND EDGAR G. HERTWICH
}

\section{Almost one-quarter of carbon dioxide released to the atmosphere is emitted in the production of internationally traded goods and senvices. Trade therefore represents an unrivalled, and unused, tool for reducing greenhouse gas emissions.}

$\mathbf{T}$ he world is currently grappling with how to handle climate change, and specifically with what form the successor to the Kyoto Protocol, whose current commitment phase expires in 2012, should take. Given the large disparities in wealth and emissions between nations ${ }^{1}$, one certainty is that climate policy cannot be applied in a globally uniform fashion, and differentiation of commitments and targets among countries is inevitable.

Although differentiated commitments make sense from a global standpoint, they can prove problematic at the national level. A particularly contentious - and complex - case in point is apportioning emissions from internationally traded products to their rightful owners. Whether the goods in question are tropically grown mangoes consumed in the US or cars shipped to the UK from Asia, such products generate a large carbon footprint through their production, international transport and consumption. Emissions from such traded goods are rising faster than the world's burgeoning population and escalating consumerism (Fig. 1).

Yet harmonizing international trade rules with climate policy has proved something of a grand challenge. Developing countries see reduced trade or emissions-related tariffs on traded goods as a threat to much needed economic growth. In the developed world, however, concerns abound over how to maintain industrial competitiveness alongside countries with less stringent, or without, emissions commitments. Energy-intensive industries, such as steel and cement manufacturers, claim that the increased costs of climate policy will force them to relocate to countries without such constraints. This not only would harm national economies, but would result in 'carbon leakage', where emissions

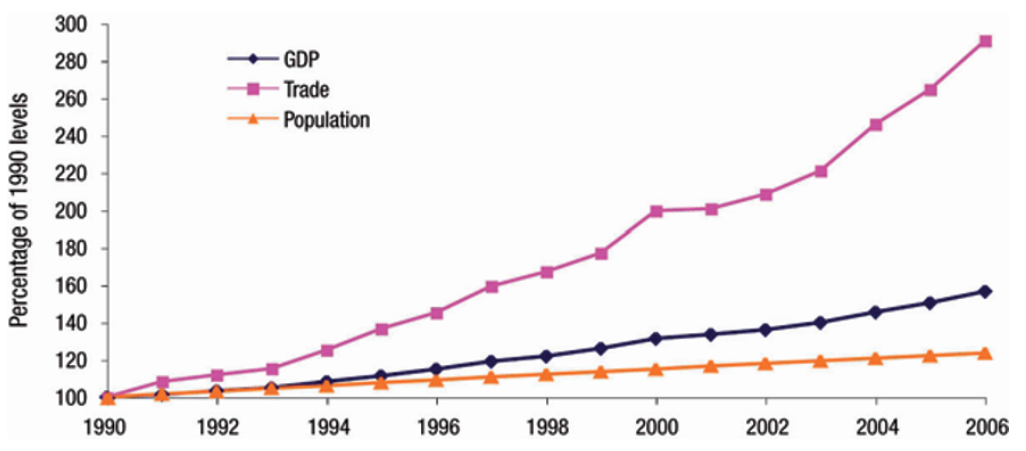

Figure 1 Rising world gross domestic product (GDP), trade and population. Since 1990, growth in trade has outpaced GDP growth ${ }^{8}$, and GDP growth has outpaced population growth ${ }^{9}$.

are merely relocated rather than being reduced. Furthermore, the import of those goods manufactured overseas will increase emissions overall.

Currently, international climate policy takes a hands-off approach to this somewhat thorny issue, with the Kyoto Protocol stating, "Parties ... shall strive to implement policies and measures ... in such a way as to minimize adverse effects ... on international trade." We argue that accounting for emissions embodied in traded goods would provide a unique opportunity to reduce greenhouse gas emissions on a global scale. First, however, there must be a critical rethink on how these emissions are defined and how carbon leakage is assessed.

\section{LEAKY CARBON}

The UN climate science body, known as the Intergovernmental Panel on Climate Change (IPCC), defines carbon leakage as the increase in greenhouse gas emissions in countries without emissions commitments that arises from reductions in emission-constrained nations - for example, from the relocation of industries abroad $^{2}$. If the problem were limited to the IPCC's definition, both theory and available data suggest that it would be negligible ${ }^{2,3}$. But a low level of carbon leakage contradicts the huge observed growth in export-related emissions from emerging economies such as China. The disparity arises because the IPCC considers only carbon leakage that results from the Kyoto Protocol, whereas, in reality, the growth in Chinese exports is due to a myriad of existing economic factors such as low labour costs and favourable exchange rates.

A broader definition of carbon leakage is therefore needed that considers all export-related emissions and not just those associated with implementing the Kyoto Protocol ${ }^{4}$. The alternative - and more policy-relevant - approach to carbon leakage is to quantify all emissions generated by each country in the production of goods and services that are traded internationally: the total 'emissions embodied in trade. This measure considers all supply-chain emissions during the production of exports, from assembly to transportation. Defined 


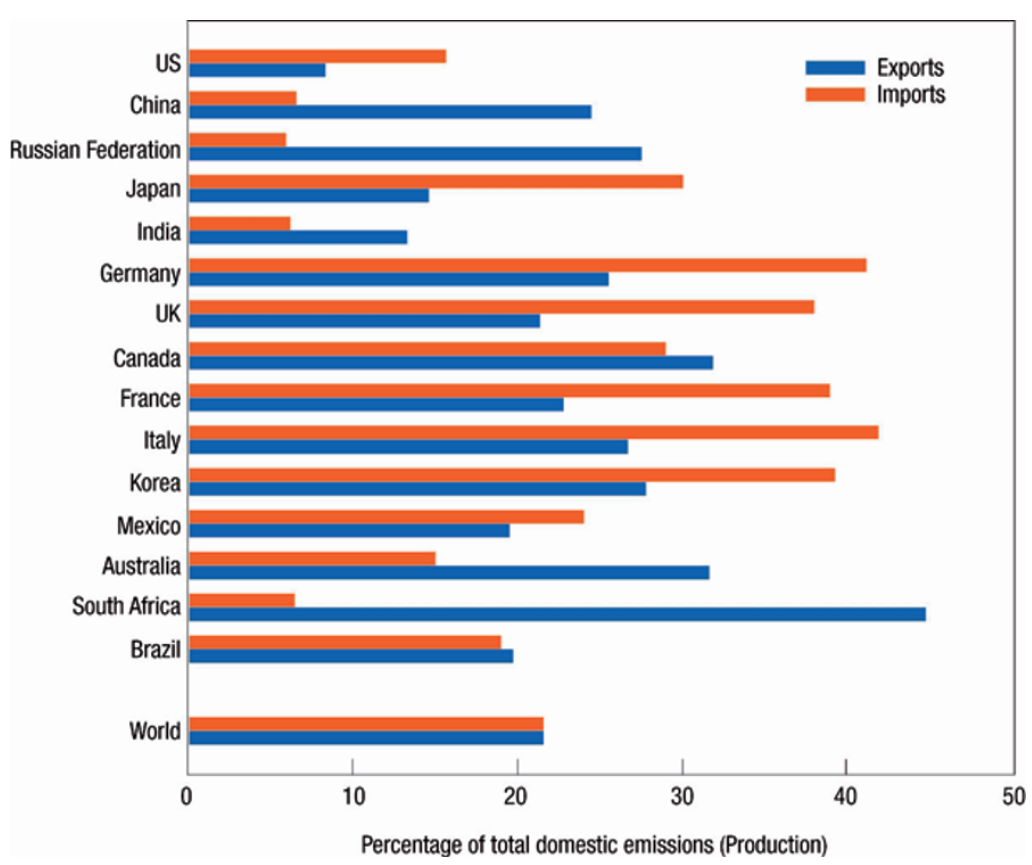

Figure 2 Emissions embodied in trade. Carbon dioxide emissions embodied in exports (blue) and imports (orange) are shown as a percentage of total domestic emissions for 2001. Included are the top 15 emitters from our model ${ }^{5}$, together with the world average. Reprinted with permission from Environmental Science \& Technology. Copyright 2008 American Chemical Society.

this way, carbon leakage constitutes all emissions embodied in exports from countries without emissions constraints to those with constraints, and it is independent of the cause of increased emissions, unlike in the IPCC definition.

Using this method, we have recently shown that internationally traded products accounted for 22 percent (5.3 gigatonnes) of global carbon dioxide emissions in 2001

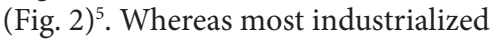
countries were net importers of carbon dioxide emissions, the reverse was true of developing countries. Moreover, according to 2001 data, of the 3.6 gigatonnes of carbon dioxide imported into developed countries, 44 percent originated in developing countries, representing a substantial source of carbon leakage.

\section{OWNING UP TO EMISSIONS}

The key to addressing trade concerns may be to understand who is responsible for traded emissions. International trade separates the country of consumption from the environmental impacts in production. But at least a portion of export-related emissions in developing economies is due to consumption in rich countries ${ }^{5}$. The emissions associated with goods consumed, rather than those produced, could be brought under the umbrella of emissions caps for developed countries. This approach would avoid directly capping emissions in developing countries, but it would still provide incentives for large-scale mitigation options in developing nations, which have comparatively lower mitigation $\operatorname{costs}^{6,7}$. A top priority would be for northern countries to invest heavily in mitigation in those southern nations that are key trading partners. For instance, foreign investments in clean electricity generation in China could drive down Chinese emissions and reduce carbon leakage in addition to providing valuable experience in the large-scale deployment of renewable technologies.
Furthermore, harmonized trade and climate policy could reduce the costs and speed the global diffusion of environmentally sound technologies, such as wind turbines. Likewise, the use of standards requiring products to meet certain environmental criteria, such as energy efficiency, could force innovation and lead to substantial savings. In the long term, production should be encouraged where there is an optimal balance among environmental, labour and capital costs ${ }^{7}$. Just as smart trade can help lift nations out of poverty, there is no reason to believe that trade cannot be used as a powerful tool to mitigate climate change.

Carbon prices on the order of US \$50-100 per tonne will be required to reduce emissions enough to stabilize greenhouse gas concentrations at acceptable levels ${ }^{2}$. And concerns about competitiveness and carbon leakage will loom significantly larger in future climate policies than in the relatively weak policies in place today. Systematic work is needed to reconcile trade and climate policy so that they can be mutually beneficial. Industrial interests will cease to oppose strict climate policies only when such work successfully removes concerns about competition and abolishes the economic advantages of non- participation in climate mitigation.

Published online: 20 March 2008

\section{doi:10.1038/climate.2008.25}

\section{References}

1. Srinivasan, U. T. et al. Proc. Natl Acad. Sci. USA 105, 1768 (2008)

2. IPCC. Climate Change 2007: Mitigation. Contribution of Working Group III to the Fourth Assessment Report of the Intergovernmental Panel on Climate Change (eds Metz, B., Davidson, O. R., Bosch, P. R., Dave, R. \& Meyer, L. A.) (Cambridge Univ. Press, Cambridge and New York, 2007).

3. Cole, M. A., Elliott, R. J. R. \& Shimamoto, K. Ecol. Econ. 54, 95 (2005).

4. Rothman, D. S. Ecol. Econ. 25, 177 (1998).

5. Peters, G. P. \& Hertwich, E.G. Environ. Sci. Technol. 42, 1401 (2008).

6. Peters, G. P. Ecol. Econ. 65, 13 (2008)

7. Peters, G. P. \& Hertwich, E.G. Clim. Change 86, 51 (2008).

8. UN Data; http://data.un.org/

9. US Census Bureau: International Data Base; http://www.census.gov/ipc/www/idb/

Glen P. Peters and Edgar G. Hertwich are in the Industrial Ecology Programme, Norwegian University of Science and Technology, Trondheim, Norway. e-mail: glen.peters@ntnu.no 